\title{
Development and Characterization of Carbon Nanotube Reinforced Aluminium-6061 Metal Matrix Composites
}

\author{
Preethi.K, Raju T.N, Shivappa H.A \\ Department of Mechanical Engineering, Dr. Ambedkar Institute of Technology, Bengaluru, India \\ Email: preethiprasannak@gmail.com
}

How to cite this paper: Preethi.K, Raju T.N and Shivappa H.A (2021) Development and Characterization of Carbon $\mathrm{Na}-$ notube Reinforced Aluminium-6061 Metal Matrix Composites. Journal of Minerals and Materials Characterization and Engineering, 9, 290-300.

https://doi.org/10.4236/jmmce.2021.93020

Received: April 15, 2021

Accepted: May 24, 2021

Published: May 27, 2021

Copyright $\odot 2021$ by author(s) and Scientific Research Publishing Inc. This work is licensed under the Creative Commons Attribution International License (CC BY 4.0).

http://creativecommons.org/licenses/by/4.0/

(c) (i) Open Access

\begin{abstract}
An emerging class of new materials is being developed with carbon nanotubes as reinforcements for Al6061 matrix material resulting in CNT-MMC composite materials. To maximize tensile strength and electrical conductivity properties of CNT materials and for the MMCs to possess optimal properties, some synthetic techniques are developed. Care is taken to ensure that these techniques are economical in production, provide uniform reinforcement dispersion in the matrix and also realize strong coherence adhesion of the CNT reinforcements and Al-6061 matrix material. Aluminum reinforced with $\mathrm{CNT}$ via powder metallurgy (PM) technique can provide a very distinct advantage. The primary drive and distinct advantage in adopting aluminum is lightweight in comparison to metal and wood composites. Besides weight savings, non-corrosive, flexible, resistance to dent, low on maintenance cost and design flexibility are the highlights of aluminum. Aluminum has wide range of application in industries because of their low density, good workability and relatively low yield strength; whereas reinforcement adds rigidity and impedes crack propagation to a great extent. Thin fibers are used as reinforcement since they possess very high strength with improved overall properties, whereas CNT has a number of invaluable and unique properties in comparison to other fibers used as reinforcement. Due to the reinforcement of CNT in aluminum, the resultant composite possesses high strength to weight ratio. In this work, the CNTs used as reinforcement with varying weight \% of 1, 1.5, 2 and Al6061 alloy as a matrix material. The composites were fabricated through powder metallurgy route. Ball milling was done to get homogeneous dispersion of CNT's. Samples were prepared as per ASTM standards for various compositions and investigated for microstructure using scanning Electron microscopy (SEM). The mechanical properties like hardness were evaluated by Micro Vickers hardness tester and compression
\end{abstract}


strength by Universal Testing Machine. The expected improvements in micro hardness and compressive strength of the MMC $s$ were achieved.

\section{Keywords}

Al-6061, CNT, MMC, Powder Metallurgy

\section{Introduction}

Carbon nanotubes are nano materials, which are gaining popularity as good reinforcements due to their distinctive properties. CNTs are attractive reinforcement materials for metal matrix composites not only due to their high strength and elastic modulus, but also due to their exceptionally small diameters. This is because, when the same weight of CNTs is contained in composites, the number of CNTs in composite increases as the diameter of CNTs becomes smaller. And, when the CNTs are uniformly dispersed in the composites, the respective matrix domains enclosed by the CNTs become extremely small. It is expected that the Aluminum composites with carbon nanotubes reinforcement would possess better tensile and compressive properties compared to pure Aluminum. The hardness of the obtained composites is also expected to be greater than that of pure aluminum. The Al-CNT composite is found to be affluent in improving the mechanical properties such that even for a small amount of CNT addition the response ineffective. The improvement in strength primarily depends on the dispersive phenomenon of CNTs and the bonding between the reinforcement (CNT) and matrix. The improvement in mechanical properties of Al-CNTs [1] also depends upon nature of processing techniques, microstructure, grain size, amount and type of reinforcement. Powder metallurgy (PM) technique is the preferred route for most researchers due to [2] most common and cheaper production route for composite fabrication and characterized by good dimensional and geometrical precision as well as good mechanical properties. Using PM process several properties of composite can be improved such as hardness, wear resistance, mechanical durability, thermal durability, and thermal conductivity with decreased density of the material. With this improvement in nanocomposite properties, the material exhibited better quality and can be used in many applications whereby demand of quality and less material are high especially in automotive and aerospace applications. Powder metallurgy and ingot melting route can be subdivided into four different methods. A composite produced by powder metallurgy route has significant influence on strength enhancement owing to fine grain size obtained by powder metallurgy route when compared with liquid phase processing. The problem of defects persists since it is difficult to avoid agglomeration of CNTs, undesirable interfacial reactions and possible damages that may occur to CNTs while adopting conventional methods of fabrication. Powder metallurgy leads to the uniform dispersion of CNTs composites associated least defects. The produced composite will have combined 
properties of its constituting elements, and this is the main reason behind the development and success of MMC manufacturing since the type and amount of the constituents of the composite could easily be altered to obtain the desired properties of the new product [3].

The present investigation emphasizes on production of Al-6061-multi wall carbon nanotube (MWCNT) metal matrix composites (MMC) wherein commercially available Al-6061 is used as base material and MWCNT with varying weight percentages of $1,1.5$ and 2 as reinforcement. It is difficult to disperse CNT wt\% greater than 2. On conducting the investigations on the mechanical strength of the fabricated composites it was observed that increase in the wt $\%$ of CNT, there was significant increase in the hardness values and compression strength.

Production of Al-6061-CNT by powder metallurgy depends on the basic overall process steps consist of mixing of CNTs with aluminum powder by grinding or mechanical alloying, followed by compaction consolidation and sintering. MMCs have some advantages over other types of matrix composites. For example, MMs outclass polymer matrices in having higher elastic modulus, resisting elevated temperatures, no moisture absorption, and their higher toughness and ductility [4]. Uniformly dispersing the reinforcing material in addition to using the appropriate consolidation process helps greatly in eliminating the segregation problem. Moreover, the properties of a specific MMC could easily be altered by changing the contents of the composite according to the application or even by changing the processing technique which opens the way for materials scientists to excel in inventing new materials with superior properties in all aspects [5].

\section{Experimental Procedure}

The chemical composition of Al 6061 alloy powder of 300-mesh size was determined by wet chemical analysis method (gravimetric method) [6] and is shown in Table 1 below.

CNTs were coated with a layer of nickel to improve the coherence bonding between MWCNTs and the matrix material. Electroless plating method is an effective approach for coating CNTs with Ni.

\subsection{Coating of CNT}

Electroless plating method is used as it can deposit many metals on almost any substrates regardless of size and shape, also the carbon nanotubes can be ultrasonically dispersed in plating solution, so each Nanotube may have probability to be coated [8]. Electroless plating is a two-step process: 1$)$ Sensitization $(0.1 \mathrm{M}$

Table 1. Chemical composition of $\mathrm{Al} 6061$ alloy [7].

\begin{tabular}{ccccccccc}
\hline $\mathrm{Mg}$ & $\mathrm{Si}$ & $\mathrm{Fe}$ & $\mathrm{Mn}$ & $\mathrm{Cu}$ & $\mathrm{Zn}$ & $\mathrm{Ti}$ & $\mathrm{Cr}$ & $\mathrm{Al}$ \\
\hline 0.9 & 0.6 & 0.7 & 0.13 & 0.32 & 0.24 & 0.12 & 0.28 & Balance \\
\hline
\end{tabular}


$\left.\mathrm{SnCl}_{2} / 0.1 \mathrm{M} \mathrm{HCl}\right) 30$ minutes; 2) Activation (0.0014 $\left.\mathrm{M} \mathrm{PdCl}_{2} / 0.25 \mathrm{M} \mathrm{HCl}\right) 30$ minutes. Preactivation of carbon nanotube was accomplished by dispersing the carbon nanotubes in a solution of $0.1 \mathrm{M} \mathrm{SnCl}_{2} / 0.1 \mathrm{M} \mathrm{HCl}$ for 30 minutes. The sensitized carbon nanotubes were further activated in an aqueous solution of $0.0014 \mathrm{M} \mathrm{PdCl}_{2} / 0.25 \mathrm{M} \mathrm{HCl}$ for another 30 minutes. The activated carbon tubes were then introduced into an electroless plating bath. The composition of plating solution and the reaction conditions are given in Table 2 . The whole procedure was carried out at $25^{\circ} \mathrm{C}$ and the carbon nanotubes were washed with distilled water after each step. The washed CNT's were heated in an oven at $150^{\circ} \mathrm{C}$ to remove the moisture present in the coated CNT. The dried CNTs were used for further ball milling, compaction and sintering processes.

\subsection{Ball Milling}

Al-CNT powders were stirred thoroughly to mix well before adding it into the ball milling urn to perform mechanical alloying on a Retch PM4000 planetary ball milling machine. The severity of the cold rolling is avoided by the addition of stearic acid ( $1 \% \mathrm{wt})$ to the urn containing the powders during the ball milling, ball to powder ratio of 5:1 was maintained and a speed of 120 RPM used throughout the process [14]. The Ball milling duration was 4 hours, with an interim duration of 10 minutes for each hour that was set to avoid overheating. After this stage, the Al-CNT blended powder was filled between the bottom and upper punch of the die, wherein the bottom punch acts as a support as well as an ejector, at the time and at the end of the compaction respectively. The sintering of the green compacted Al-CNT composite was carried out at $600^{\circ} \mathrm{C}$ [15] for 2 hours in a muffle furnace (Figure 1).

\subsection{Sample Preparation for Microscopy Study}

Scanning electron microscope (SEM) is a tool for the characterization of materials from nanometer to micrometer scale. It is one of the most versatile instruments that are available for the examination and analysis of the microstructure morphology. Before observing the microstructure, the surface is prepared. First

Table 2. Shows bath composition and operating conditions of electroless nickel coating [8]-[13].

\begin{tabular}{ccc}
\hline Sl no & Chemical & Concentration \\
\hline 1 & $\mathrm{NiCl}_{2} \cdot 6 \mathrm{H}_{2} \mathrm{O}$ & $59.4 \mathrm{~g} / \mathrm{L}$ \\
2 & $\mathrm{NiSO}_{4} \cdot 6 \mathrm{H}_{2} \mathrm{O}$ & $23.65 \mathrm{~g} / \mathrm{L}$ \\
3 & $\mathrm{NaH}_{2} \mathrm{PO}_{2} \cdot 2 \mathrm{H}_{2} \mathrm{O}$ & $104.16 \mathrm{~g} / \mathrm{L}$ \\
4 & $\mathrm{NH}_{4} \mathrm{Cl}$ & $100 \mathrm{~g} / \mathrm{L}$ \\
5 & $\left.\mathrm{~Pb} \mathrm{NO}_{3}\right)_{2}$ & $2.848 \mathrm{~g} / \mathrm{L}$ \\
6 & $\mathrm{pH}$ at $25^{\circ} \mathrm{C}\left(\right.$ adjusted by $\left.\mathrm{NH}_{4} \mathrm{OH}\right)$ & $8.75 \mathrm{pH}$ \\
7 & $\mathrm{Bath}$ temperature & $25^{\circ} \mathrm{C}$
\end{tabular}




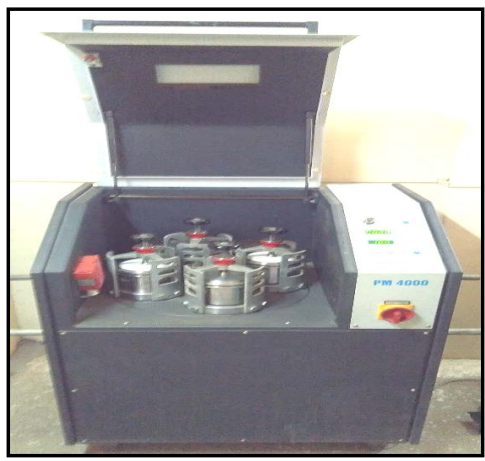

(a)

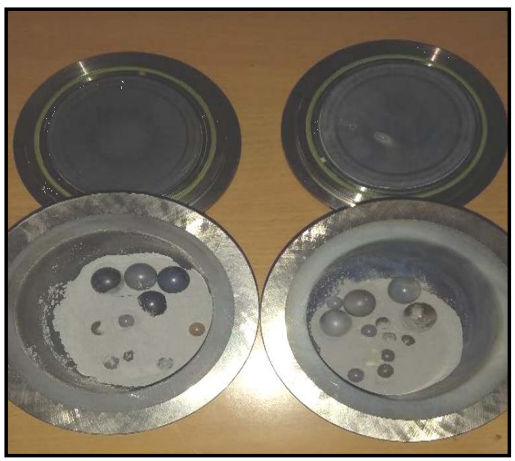

(b)

Figure 1. (a) Four jar planetary Ball milling machine (RETZEH PM400); (b) Ball mill Jar with Stainless steel balls.

the specimen surface was cleaned using a cotton swab and ethyl alcohol. After this, polish the section on 800 grit emery paper in single direction and note that no excess pressure is applied during the process as it may lead to permanent scarring on the surface. The specimen is rotated by $90^{\circ}$ and the same procedure is followed on a 1000 grit sand paper [16]. The surface is cleaned at each stage with cotton swab and ethyl alcohol before taking a finer Emery paper (1200, 1500,1800 , and 2000 grit size). The cleaning with ethyl alcohol is necessary to make sure that abraded particles or the soot do not get embedded on the specimen surface. After achieving a near smooth surface, further polishing is done using a velvet cloth and diamond paste. The diamond paste is applied to the surface to be polished; velvet cloth is fixed to a disc spinning at a fixed rpm. The specimen with the applied diamond paste is pressed against the rotating velvet cloth. Due to the friction, the diamond paste polishes the surface. This process is carried out till the required finish is obtained.

\subsection{Differential Thermal Analysis (DTA)}

The differential thermal analysis was performed on the Al-CNT MMCs which was subjected to continuous increase in temperature at a constant heating rate and linear with time. $10 \mathrm{mg}$ of Al-CNTs were placed in a pan inside the setup and DTA was performed at a heating rate of $10^{\circ} \mathrm{C} / \mathrm{min}$ to keep a continuous record till it reaches the melting point as shown in Figure 2 [17].

\section{Results and Discussion}

\subsection{Transmission Electron Microscopic (TEM) Analysis}

Transmission Electron microscopy (TEM) was performed on the coated CNTs. Figure 3 clearly shows that $\mathrm{Ni}$ is coated on the carbon nanotube evenly.

Transmission electron microscope (TEM) micrographs of multiwall carbon nanotubes (MWCNT) and coated MWCNT are shown in Figures 3(a)-(f). Based on the TEM micrograph Figure 3(e) the inner diameter of MWCNT is in the range of 12.91 to $20 \mathrm{~nm}$ and the outer diameter is in the range of 17.93 to 30 $\mathrm{nm}$. It can also be observed from the micrograph that the ends of MWCNT are 


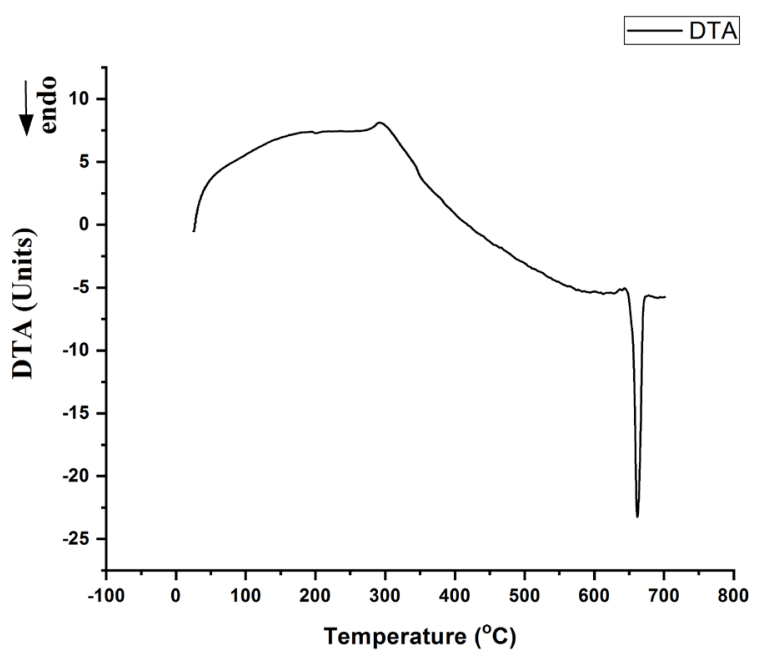

Figure 2. DTA graph for Al-CNT.

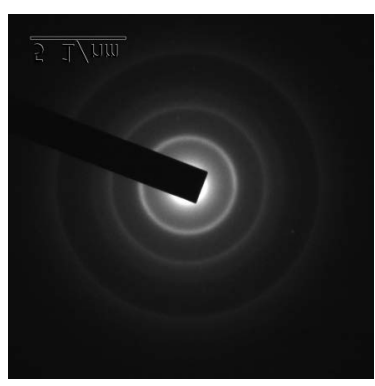

(a)

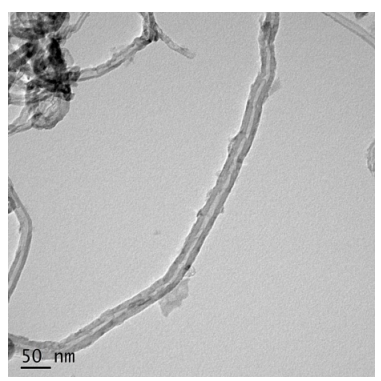

(d)

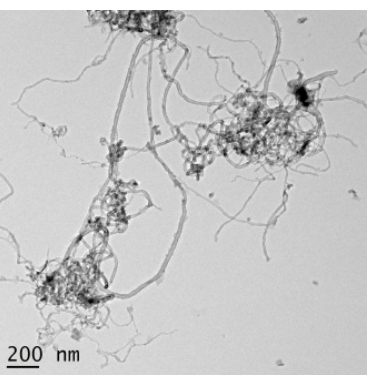

(b)

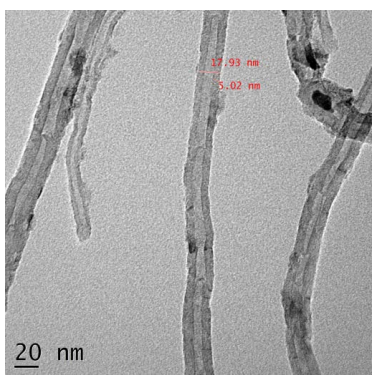

(e)

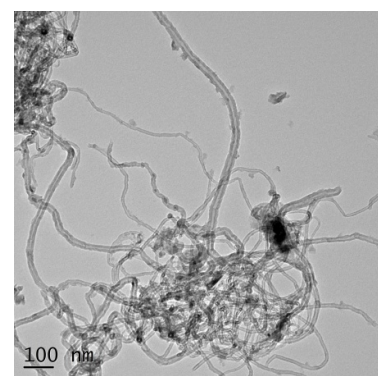

(c)

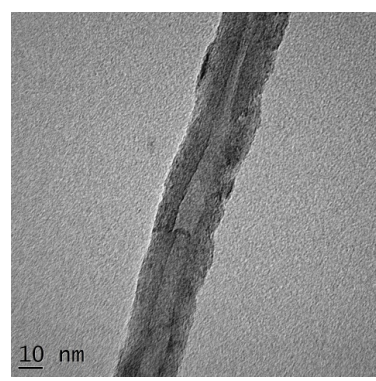

(f)

Figure 3. (a) TEM diffraction (b) high resolution Ni coated CNT (c) Ni coating on CNTs (d) Ni coating on CNTs, (e) CNT without coating, and (f) high resolution CNT without coating.

closed in the form of end caps. Figures 3(b)-(d) show a well decoration of MWCNT with nickel (Ni) and also the Ni nano particles are closely attached to the MWCNT surface. The coating thickness or the average size of Ni nano particles is in the range of $5-20 \mathrm{~nm}$. In addition to this, the Ni particles are spread homogeneously on the outer surface of MWCNT.

It can also be observed from Figures 3(b)-(d) that $\mathrm{Ni}$ appears as aggregates on the outer surface of the nanotubes indicating the activated sites were formed. $\mathrm{Ni}$ on coating appears as balls on the outer surface of carbon nanotubes. Also the $\mathrm{Ni}$ coating layer on the nanotube is discontinuous, this is probably due to ab- 
sence of active sites or due to the formation of nonuniform active sites on the surface of the nanotube. This is attributed to the rate of reaction which is dependent on the $\mathrm{pH}$ value of the solution which can be adjusted by varying the concentration of $\mathrm{NH}_{3} \cdot \mathrm{H}_{2} \mathrm{O}$ [9].

\subsection{Scanning Electron Microscopic (SEM) Analysis}

The microstructures of the specimens are taken for $0 \%, 1 \%, 1.5 \%$ and $2 \%$ composition of the reinforcements are studied. From Figure 4 and Figure 5 microstructure study shows good bonding between matrix and reinforcement with fairly distinguishable grain boundaries. The observations showed that CNT

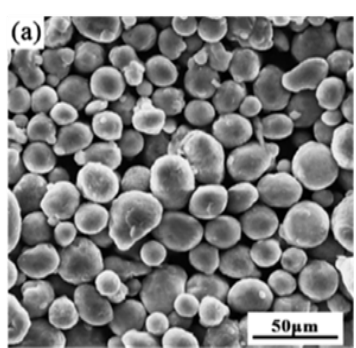

(a)

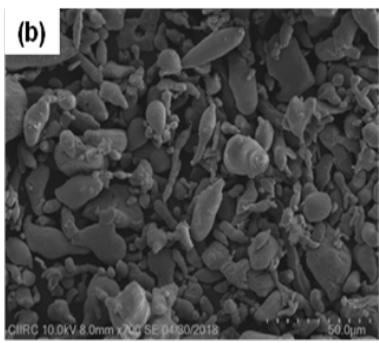

(b)

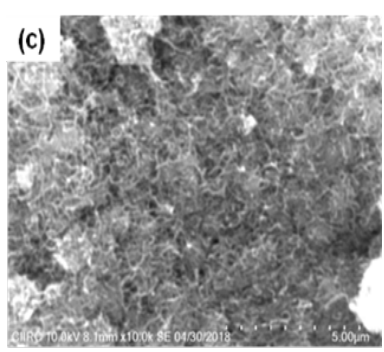

(c)

Figure 4. (a) Al-6061 powder with average gain size of $25 \mu \mathrm{m}$ (b) ball milled Al-6061 powder (c) entangled CNTs.

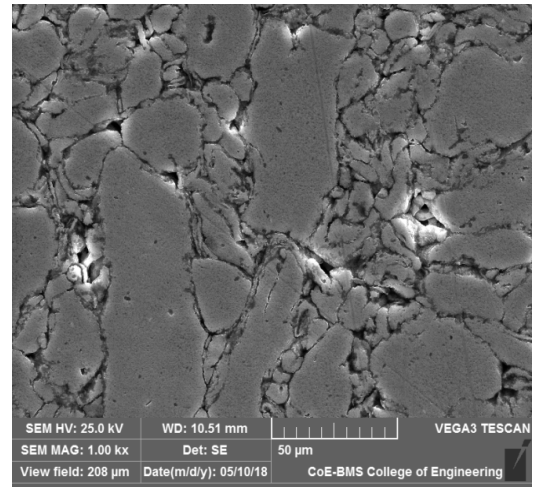

(a)

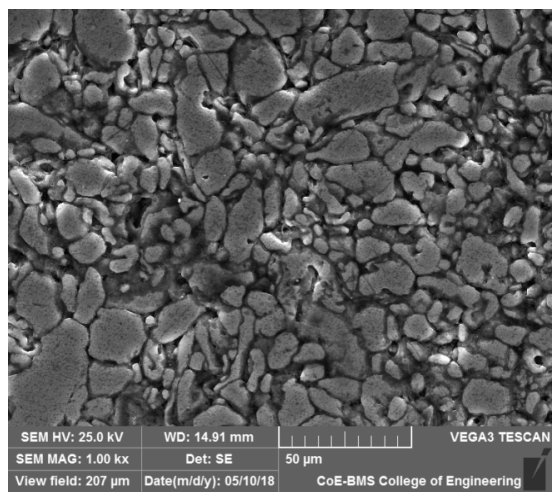

(c)

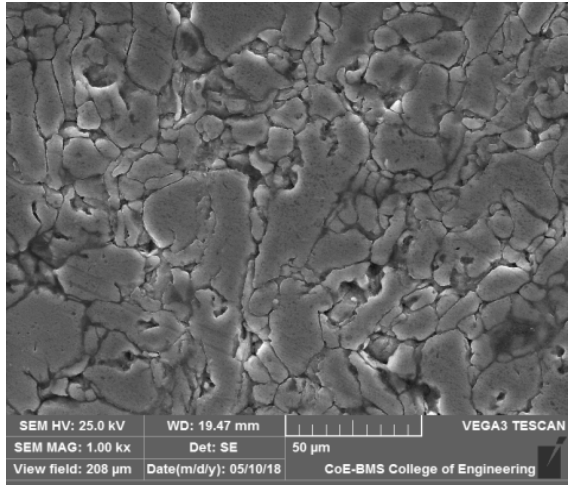

(b)

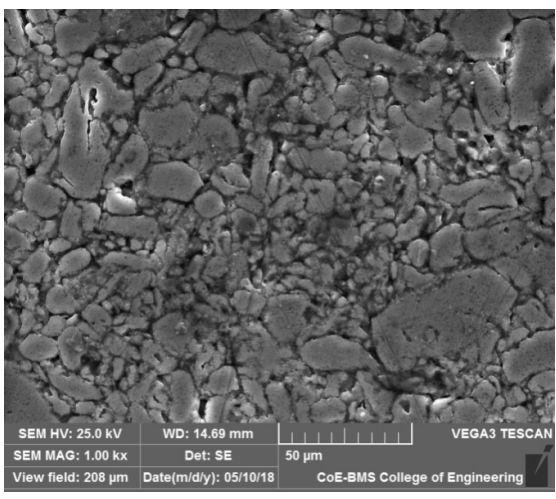

(d)

Figure 5. Microstructure of (a) $0 \%$; (b) $1 \%$; (c) $1.5 \%$ and (d) $2 \%$ reinforcements. 
reinforcement was dispersed uniformly into the aluminum matrix. This leads to strengthening of the composite at the microscopic level and enhancing the mechanical properties of the composite as compared to its unmixed counterpart.

\subsection{Micro Vickers Hardness and Compression Test}

The fabricated specimens are named as pure aluminum $\mathrm{S} 1,1 \mathrm{wt} \%$ of CNT as $\mathrm{S} 2$, $1.5 \mathrm{wt} \%$ of CNT as S3 and $2 \mathrm{wt} \%$ of CNT as S4. Since the specimens are smaller in dimension, the usual hardness test cannot be conducted on it as the ball indenter might break the specimen. Hence Micro Vickers hardness tests were conducted on the specimens to compare their hardness, which is appropriate for the chosen dimension of the specimen. The tests were conducted by WILSON-VH1102, BUEHLER, make hardness tester and test results recorded using diamet software. The machine has Magnification of $10 \times$ to $50 \times$, load range $10 \mathrm{gm} 2 \mathrm{~kg}$ with a diamond indenter and square base pyramidal shape. A total of five indentations were recorded with a distance of $1 \mathrm{~mm}$. with a load of $0.5 \mathrm{~kg}$ and average value was noted to maintain consistency.

From Table 3, it is observed that there is an increase in the hardness of the specimens reinforced with varying wt\% of CNT as compared to pure Al6061 alloy (0 wt\% CNT). From Figure 6, it can be observed that the $\mathrm{Al}$ alloy with $2 \mathrm{wt} \%$ $\mathrm{CNT}$ as reinforcement shows higher hardness when compared to other specimens. It is also observed that the specimen $\mathrm{S} 4$ with $2 \mathrm{wt} \% \mathrm{CNT}$ as reinforcement shows 32\% increase in the strength when compared to unreinforced Al6061 alloy.

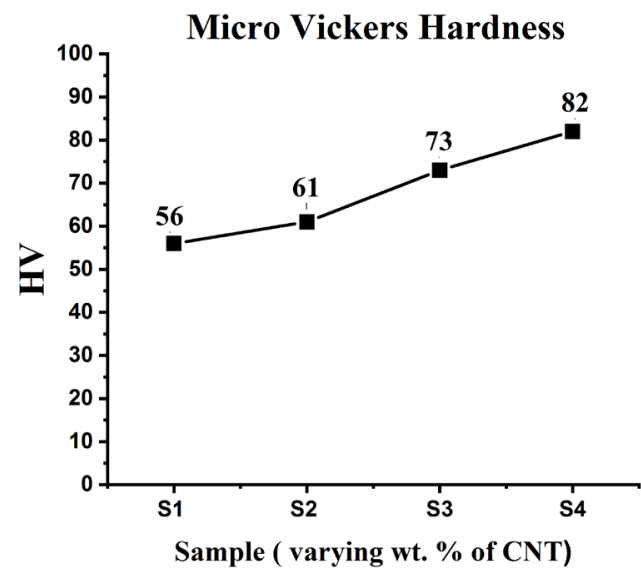

Figure 6. Hardness values for different wt\% of CNT samples.

Table 3. Micro hardness properties and compression strength of Al-6061 alloy.

\begin{tabular}{ccc}
\hline Specimen & Micro Hardness (HV) & Compressive Strength in MPa \\
\hline S1 & 56 & 157 \\
S2 & 61 & 161 \\
S3 & 73 & 169 \\
S4 & 82 & 179 \\
\hline
\end{tabular}




\subsection{Compression Test}

The compression test is carried out on the specimen to find out the compression strength of the composite synthesized. Compression test were carried out in a Computerized Universal Testing Machine with a capacity of $1000 \mathrm{KN}$ (Figure 7). Specimens are of standard cylindrical shape having $1 / \mathrm{d}$ ratio less than 2 (short specimen) were prepared as per ASTM standard EN09. From Figure 8, it can be observed that compressive strength increases with increase in the percentage of CNT up to $2 \mathrm{wt} \%$. Higher value is observed in the sample S4 having $2 \mathrm{wt} \%$ of $\mathrm{CNT}$ as reinforcement. This clearly indicates that the increase in the strength is attributed to the presence of CNT in the matrix which acts as an obstacle for crack propagation in turn increasing the strength of the composites. It is also clear that there is adequate bond between the CNT reinforcement and the Al-6061 matrix material. It is also observed that the specimen S4 with $2 \mathrm{wt} \%$ CNT as reinforcement shows $12 \%$ increase in the strength when compared to unreinforced Al-6061 alloy.

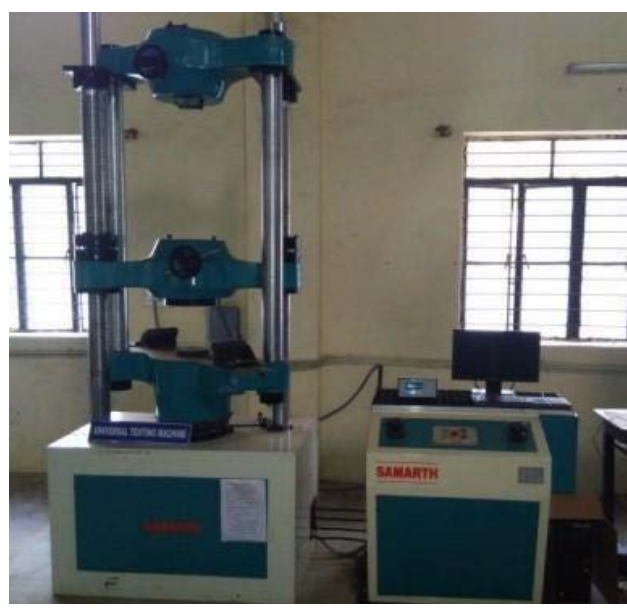

Figure 7. Compaction machine (UTM).

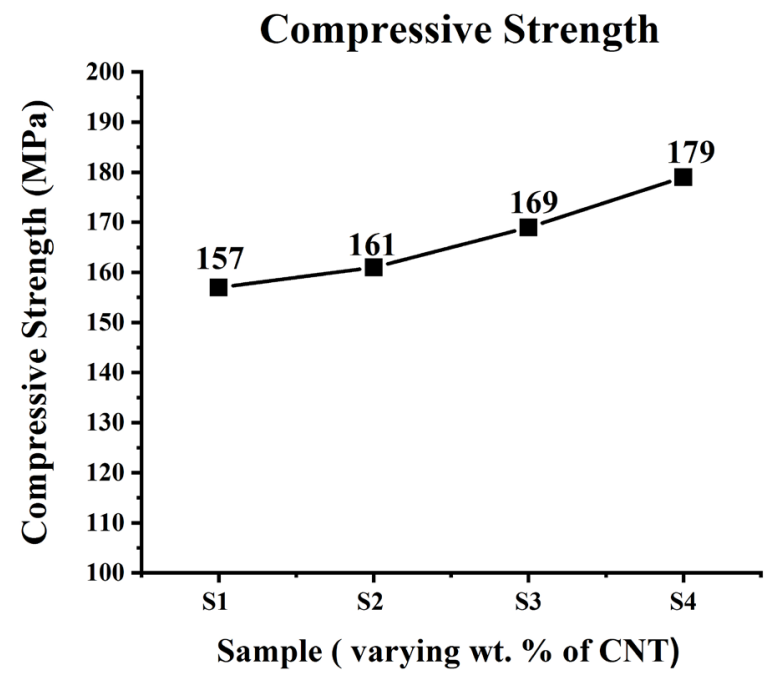

Figure 8. Compressive strength values for different wt $\%$ of CNT samples. 


\section{Conclusion}

Al-6061 powder matrix mixed with MWCNT in weight percentages of $0,1,1.5$ and 2 weight percentage as reinforcement was produced through powder metallurgy route and the specimens were sintered, evaluated for their microstructure and mechanical properties such as compression strength and hardness. From the results, it was concluded that ball milling process has decreased the grain size of the Aluminum powder and ensured even dispersion of CNT without agglomeration taking place. Microstructure study shows good bonding between matrix and reinforcement with distinguishable grain boundaries. The Hardness value of Al-CNT metal matrix to that of pure Al-6061 alloy has increased from 56 to 82 VHN which is about $32 \%$ increase. The compressive strength has increased to $12 \%$ with the value of 157 to $179 \mathrm{MPa}$ when compared to pure Al-6061 to that of Al-6061 alloy reinforced with 2 wt\% CNT.

\section{Acknowledgements}

The authors are grateful to the research and development laboratory facilities provided by the Department of Mechanical Engineering at Dr. Ambedkar Institute of Technology, Bengaluru for carrying out this project work successfully.

\section{Conflicts of Interest}

The authors declare no conflicts of interest regarding the publication of this paper.

\section{References}

[1] Bakshi, S.R., Lahiri, D. and Argawal, A. (2010) Carbon Nanotube Reinforced Metal Matrix Composites-A Review. International Materials Reviews, 55, 41-64. https://doi.org/10.1179/095066009X12572530170543

[2] Rams, J., Urena, A., Escalera, M.D. and Sanchez, M. (2007) Electro-Less Nickel Coated Short Carbons in Aluminium Matrix Composites. Journal of Composites. Part A: Applied Science and Manufacturing, 38, 566-575. https://doi.org/10.1016/j.compositesa.2006.02.010

[3] Drukin, C. (2007) Low-Cost Continuous Production of Carbon Fiber reinforced Aluminum Composites. Material Science and Engineering, Georgia Institute of Technology, Atlanta.

[4] Urena, A., Rams, J., Escalera, M.D. and Sanchez, M. (2007) Effect of Copper Electroless Coatings on the Interaction between a Molten Al-Si-Mg Alloy and Coated Short Carbon Fibers. Journal of Composites. Part A: Applied Science and Manufacturing, 38, 1947-1956. https://doi.org/10.1016/j.compositesa.2007.02.005

[5] Preethi, K., Raju, T.N., Shivappa, H.A., Shashidhar, S. and Nagral, M. (2021) Processing, Microstructure, Hardness and Wear Behavior of Carbon Nanotube Particulates Reinforced Al6061 Alloy Composites. Materials Today. Proceedings, 2214-7853. https://doi.org/10.1016/j.matpr.2021.03.608

[6] Popovska, N., Gerhard, H., Wurm, D., Poscher, S., Emig, G. and Singer, R.F. (1997) Chemical Vapor Deposition of Titanium Nitride on Carbon Fibers as a Protective Layer in Metal Matrix Composites. Journal of Materials and Design, 18, 239-242. 
https://doi.org/10.1016/S0261-3069(97)00057-5

[7] Lee, W.-S., Sue, W.-C. and Lin, C.-F. (2000) The Effects of Temperature and Strain Rate on the Properties of Carbon Fiber Reinforced 7075 Aluminium Alloy Metal Matrix Composite. Journal of Composite Science and Technology, 60, 1975-1983. https://doi.org/10.1016/S0266-3538(00)00083-X

[8] Chen, H. and Alpas, A.T. (1996) Wear of Aluminium Matrix Composites Reinforced with Nickel Coated Carbon Fibers. Wear, 192, 186-198. https://doi.org/10.1016/0043-1648(95)06795-7

[9] Li, Q., Fan, S., Han, W., Sun, C. and Liang, W. (1997) Coating of Carbon Nanotube with Nickel by Electroless Plating Method. Japanese Journal of Applied Physics, 36, L501-L503. https://doi.org/10.1143/JJAP.36.L501

[10] American Society for Metals (2001) ASM Hand Book, Composites. Vol. 21, 10th Edition, ASM International Publication, Novelty.

[11] Bakshi, S.R. and Agarwal, A. (2011) An Analysis of the Factors Affecting Strengtheningin Carbon Nanotube Reinforced Aluminium Composites. Carbon, 49, 533-544. https://doi.org/10.1016/j.carbon.2010.09.054

[12] Esawi, A.M.K, Morsi, K., Sayed, A., Taher, M. and Lanka, S. (2010) Effect of carbon nanotube $(\mathrm{CNT})$ content on the mechanical properties of CNTreinforced aluminium composites. Composites Science and Technology, 70, 2237-2241.

https://doi.org/10.1016/j.compscitech.2010.05.004

[13] Van Trinh, P., Van An, N., Hung, T.B., Danh, C.L., Van Chuc, N., Van Chuc, N., et al. (2013) A Method to Obtain Homogeneously Dispersed Carbon Nanotubes in Al Powders for Preparing Al/CNTs Nanocomposite. Advances in Natural Sciences. Nanoscience and Nanotechnology, 4, Article ID: 025015. https://doi.org/10.1088/2043-6262/4/2/025015

[14] Devanshu, S., Amulya, K. and Murtaza, Q. (2015) CNT Reinforced Aluminium Metal Matrix Composite-A Review. Materials Today, 2, 2886-2895.

https://doi.org/10.1016/j.matpr.2015.07.248

[15] George, R., Kashyap, K.T., Rahul, R. and Yamdagni, S. (2005) Strengthening in Carbon Nanotube/Aluminium (CNT/Al) Composites. Scripta Materialia, 53, 1159-1163. https://doi.org/10.1016/j.scriptamat.2005.07.022

[16] Jayasimman, D., Sivasankaran, K. and Narayanaswamy, R. (2014) Fabrication and Consolidation Behavior of Al 01 Nanocomposite Powders Reinforced by Multi-Walled Carbon Nanotubes. Powder Technology, 258, 189-197. https://doi.org/10.1016/j.powtec.2014.03.039

[17] Esawi, A.M.K, Morsi, K., Sayed, A., Taher, M. and Lanka, S. (2011) The Influence of Carbon Nanotube (CNT) Morphology and Diameter on the Processing and Properties of CNT-Reinforced Aluminium Composites. Composites Part A: Applied Science and Manufacturing, 42, 234-243. https://doi.org/10.1016/j.compositesa.2010.11.008 